\title{
PROBLEMAS PSICOLÓGICOS ADVINDO DA BUSCA PELO CORPO BELO NO CONTEXTO DA MAIORIA SOCIAL
}

\section{REVISÃO BIBLIOMÉTRICA}

TAKAHASHI, Andressa Yumi ${ }^{1}$

TAKAHASHI, Andressa Yumi. Problemas psicológicos advindo da busca pelo corpo belo no contexto da maioria social. Revista Científica Multidisciplinar Núcleo do Conhecimento. Ano 05, Ed. 09, Vol. 09, pp. 23-34. Setembro de 2020. ISSN: 24480959, Link de acesso: https://www.nucleodoconhecimento.com.br/psicologia/corpo$\underline{\text { belo }}$

\section{RESUMO}

O objetivo desse escrito consistiu em trazer a problemática do culto ao corpo belo na contemporaneidade, apresentando a construção histórica do corpo feminino até o século XXI bem como a controversa do padrão de beleza imposto pela mídia e sociedade capitalista que acarreta quadros patológicos e em prejuízos biopsicossociais. Para tanto se utilizou da pesquisa bibliográfica, no âmbito social e psicanalítico Freudiano a qual teve como principal resultado a relação entre o corpo feminino para o outro e os distúrbios alimentares.

Palavras-Chaves: corpo feminino, padrão de beleza, mídia, capitalismo, transtornos alimentares.

\section{INTRODUÇAO}

Vivemos em uma sociedade a qual apresenta uma variedade de possibilidades de alterações corporais a fim de corresponder o culto ao corpo belo na contemporaneidade. Essa temática traz problemáticas a serem discutidas uma vez

${ }^{1}$ Graduação em andamento em Psicologia. 
que traz prejuízos a saúde mental das pessoas afetadas pela alienação quanto ao seu corpo sustentado pela indústria do emagrecimento.

Partindo desses princípios e compreendendo o corpo como uma construção sociocultural, o presente estudo tem como objetivo discutir, a partir da visão social e psicanalítica, a influência dos interesses do sistema capitalista juntamente a exibição de representações sociais sobre a distorção das imagens e os transtornos alimentares.

Michel Foucault (1987) afirma que:

[...] em qualquer sociedade, o corpo está preso no interior de poderes muito apertados, que the impõem limitações, proibições ou obrigações. [...] Forma-se então uma política das coerções que é um trabalho sobre o corpo, uma manipulação calculada de seus elementos, de seus gestos, de seus comportamentos. O corpo humano entra numa maquinaria de poder que o esquadrinha, o desarticula e o recompõe. (FOUCAULT, 1987, p.119).

Através dessa citação, percebe-se a forma de controle social relacionado ao corpo, chamamos esse fenômeno como pressão estética, que se expõe como fator desencadeador de distúrbios alimentares bem como outros transtornos psiquiátricos. Essa pressão estética proveniente de vetores como indústrias de beleza e capitalismo estão cada vez mais presentes nas campanhas publicitárias e produtos midiáticos produzindo crenças deturpas, a qual acredita-se que o corpo é totalmente maleável desconsiderando fatores genéticos e biológicos e a crença de que ao adquirir o corpo idealizado terá sucesso em outras áreas da vida: fruto de uma sociedade onde há uma estigmatização ao se tratar do intelecto da mulher e também produto de uma construção sociocultural em que as conquistas das mulheres são ofuscadas meramente pelo peso e corpo.

Os empenhos dedicados em torno do corpo ideal, que atualmente compõe-se como uma ideia irrealizável, são justificados pela sua identificação como um novo modelo de felicidade humana. Como explica Silva (2001, p.55), a passagem para esse novo universal "[...] dá-se por meio da tecnologia que investe profundamente nas questões 
do corpo, ela mesma identificada com o progresso e a serviço do mercado, que busca se expandir ilimitadamente".

A pesquisa bibliográfica abrangeu artigos publicados em periódicos de saúde pública e mental, a partir das palavras-chave: corpo feminino, transtornos alimentares, mídia e subjetividade, capitalismo, indústria de beleza, feminilidade e psicanálise.

\section{FEMINILIDADE E PSICANÁLISE}

$\mathrm{Na}$ Psicanálise as discussões sobre o corpo da mulher iniciam-se com os estudos sobre a histeria. Foi devido às observações clínicas de mulheres histéricas que Freud desenvolveu sua teoria, além disso, foi a primeira formulação não médica sobre o corpo. Segundo autores como Birman (1998) e Garcia-Roza (1990) a Psicanálise é uma ciência do psiquismo, ou seja, o corpo de que ela trata não é o corpo anatômico, mas sim o corpo construído pela cultura. Esse tópico tem como objetivo analisar o desenvolvimento da feminilidade como posições construídas psiquicamente, pois "Freud constata que ninguém nasce mulher, esta condição é construída". (TOMAZ, 2001, p. 81).

Na infância só existe um único sexo: o masculino por sua vez então a feminilidade não existe desde o princípio para uma menina, ela só vai poder assumir a posição feminina quando ela assume uma condição materna a qual enfraquece também a inveja do pênis. Ou seja, naquele contexto sócio histórico, Freud vincula a feminilidade com a maternidade e passividade e o bebê então caracteriza se como o falo da mulher.

De antemão, Lacan revê as obras freudianas e ao contrário de Freud, Lacan afirma que não há um significante único que irá definir o que é ser mulher, isto significa dizer que a compreensão sobre a mulher não é universal e a feminilidade não precisa estar necessariamente ligada à maternidade. A mulher é uma anatomia própria e singular construída através do cenário fantasmático de cada um, portanto é necessário compreender a singularidade e subjetividade de cada mulher.

[...] a noção de feminilidade pode ajudar tanto a compreender as formas contemporâneas de subjetivação quanto a criar espaços para a 
diversidade, a alteridade e a singularidade, tarefa da qual nós analistas não devemos nos furtar (NUNES, 2002, p.57).

\section{CONSTRUÇÃO HISTÓRICA DO CORPO FEMININO}

O corpo é o signo de uma história, ou seja, ele não se compreende apenas com fatores biológicos e fisiológicos, mas como produto de uma construção cultural, histórica e social. Para Silvana Goellner (2003):

O corpo é também o que dele se diz e aqui estou a afirmar que o corpo é construído, também, pela linguagem. Ou seja, a linguagem não apenas reflete o que existe. Ela própria cria o existente e, com relação ao corpo, a linguagem tem 0 poder de nomeá-lo, classificá-lo, deferir-lhe normalidades e anormalidades, instituir, por exemplo, o que é considerado como corpo belo, jovem e saudável. Representações estas que não são universais nem mesmo fixas. São sempre temporárias, efêmeras, inconstantes e variam conforme o lugar/tempo onde este corpo circula, vive, se expressa, se produz e é produzido. (Idem. Ibid: 29).

Ou seja, é através da linguagem que se institui o conceito de "belo" e foi através das mudanças históricas do conceito de corpo perante a influência da mídia e do capitalismo, que emergiram novas práticas voltadas ao próprio corpo.

Os ideais de beleza de hoje não são os mesmos desde sempre. O corpo imaginário social feminino sofre várias transformações. Desde a Antiguidade se tem notícias das práticas sociais de beleza, mas conforme dito anteriormente, o conceito de corpo varia conforme o momento sócio cultural que estamos vivenciando.

Nos séculos XII e XIII, as roupas como o espartilho eram usadas para acentuar a silhueta destacando os atributos considerados como femininos bem como mostrar o poder que seu marido tinha: os homens viam as mulheres como seus cabides e para poder ostentar, colocavam nelas as peças que podiam pagar. Contudo, no século XIX, o espartilho foi colocado em desuso devido ao discurso dos higienistas, que afirmavam que o espartilho era causador de deformações nos corpos femininos.

Então, ao longo do século XX, o corpo humano era sinônimo de saúde e bem estar. Foi em 1930 que o culto ao corpo belo e magro foi inserido na mídia juntamente com 
anúncio sobre cirurgias plásticas e intervenções estéticas. Já nas décadas de 40 e 50 a referência de feminilidade era Marylin Monroe com seu quadril largo e seios fartos.

A partir da década de 60 a beleza física deixa de ser um tabu, o que acabou fomentando o uso de cosméticos, realização de cirurgias estéticas, reproduzindo o corpo como produto e objeto social.

Atualmente, o corpo feminino sofre uma pressão estética através da indústria de beleza e das mídias que determinam uma forma padronizada de concepção da beleza feminina: sem flacidez, corpos bem definidos, cintura fina, seios e nádegas firmes e arredondados. Vive-se na era das imagens, na qual a perfeição estética do corpo é prevalente e reforçada por modelos inatingíveis, as mulheres vivem em uma incessante busca pelo "corpo ideal" reforçado através da mídia, com a tentativa de serem aceitas pela sociedade e muitas acabam adoecendo pelos mecanismos utilizados para manter a rentabilidade em volta do culto ao corpo.

\section{INDÚSTRIA DE BELEZA E CAPITALISMO}

A cultura do consumo, intimamente ligada com o desenvolvimento da industrialização, gerou uma necessidade de expansão da moda e beleza fundamentada no conceito do "corpo reconstituído", ou seja, passível de mudanças através de experiências, práticas e produtos estéticos. Nesse sentido, o corpo e a imagem tornam se um campo de atuação fundamental do movimento capitalista expandindo assim, a indústria de beleza, o mercado de bens e serviços destinados à manutenção do corpo.

O capitalismo se desenvolveu no final do século XVIII e início do século XIX e com isso tornou o corpo feminino como principal força de produção e força de trabalho, isso devido à insatisfação que as mulheres demonstram frente ao seu próprio corpo por conta dos padrões de belezas impostos pela sociedade. Então, as indústrias de beleza criam produtos e as características humanas passam a ser conferidas como mercadorias. João Bernardo (2004, p.68) afirma que: “[...] é a própria pessoa física que se pretende moldar, e os padrões não são escolhidos pelos consumidores, mas 
impostos maciçamente pelas mesmas empresas que vendem os produtos e os serviços de beleza".

Por conseguinte, a partir do capitalismo a beleza passou a ser comprada, o mercado de beleza começa a oferecer inúmeras opções de procedimentos estéticos bem como produtos de beleza para "tornar uma mulher mais bela". O corpo acaba gerando então o abandono do SER e partindo para o uso do TER da mesma forma que a subjetividade acaba sendo reduzida ao corpo. Hoje, o eu é o corpo.

Tal como descreve Costa (2004)

[...] satisfação com dois ideais de prazer difundidos na cultura atual. $O$ primeiro corresponde aproximadamente ao que o senso comum crítico ou ordinário chama de 'hedonismo' ou 'narcisismo'. Este é o sentido menos evidente e mais pedestre da expressão. Admite-se, sem fundamento empírico, que a maior parte dos sujeitos hoje condicionou a satisfação ou a autorrealização pessoal ao gozo do êxtase sensorial. É a tese do sujeito 'colecionador de sensações', em sua versão moralista ou preconceituosa (COSTA, 2004a, p. 92).

Isto é, através dos padrões impostos pela sociedade sobre a beleza e o corpo ideal, cada vez mais estamos sendo orientados pelo desejo de TER o corpo e não SER. Sendo assim, vivemos em um narcisismo pautado pelo que a cultura definiu, constituída de processos de identificações e constituições do aparelho psíquico.

A necessidade do mercado dos cirurgiões torna-se imaginário já que não há nada de errado com a aparência física das mulheres, uma vez que uma mudança social pudesse resolver. Por isso que, para obtenção de suas rendas, cirurgiões são dependentes da deformação da percepção e intensificação do ódio em si mesma por parte das mulheres. (WOLF, 1990).

O capitalismo juntamente com as indústrias de beleza usam de técnicas, procedimentos, regimes, cosméticos como força de opressão as mulheres decorrendo se de reflexos distorcidos sobre sua própria autoimagem corporal. Ou seja, para as indústrias de beleza é vantajoso que as mulheres estejam insatisfeitas com seu próprio corpo. 


\section{O CORPO DA MULHER CONTEMPORANEA EM REVISTAS E MÍDIAS}

O consumo não se dá apenas pelas indústrias de beleza, mas também através das redes sociais em que mostram uma realidade forjada e fragmentada. A mídia constitui o sujeito em relação ao outro a qual impossibilita e dificulta o processo de fabricação de subjetividades das mulheres uma vez que a mídia e as indústrias de beleza instituem, juntamente com a possibilidade de escolhas ofertados pelo mercado, um modelo padronizado de corpo belo.

As estratégias de publicidade disponibiliza uma falsa imagem, produzindo indivíduos com a autoimagem distorcida. Principalmente as mulheres, são bombardeadas por propagandas de inúmeros produtos, muitas vezes enganosas e superestimada, que prometem um resultado irreal. Isso pode ser observado no comportamento de inúmeras digitais influencer, que muitas vezes ocultam suas cirurgias plásticas, ao publicizar cremes e cintas como responsáveis pelo seu "corpo perfeito".

Ademais, outra pauta a se tratar em relação à mulher contemporânea em revistas e mídias são as questões de representações sociais. O modelo de propagação de padrão de beleza, apresentado em mídias e revistas, se torna um fator problemático, pois coloca como um canal influente gerando mudanças de comportamento, emoções e sentimentos devido à insatisfação crônica com o seu corpo. Em outros termos, atualmente a mídia exerce um papel muito influente nas práticas dos indivíduos a qual acaba sendo produtor de violência simbólica, pois torna as mulheres cada vez mais homogêneas e fáceis de serem enganadas pela publicidade, excluindo e invisibilizando então outros corpos além daquele dito "corpo ideal".

Para Pierre Bourdieu, a violência simbólica é cometida com a cumplicidade entre quem sofre e quem a prática, sem que, frequentemente, os envolvidos tenham consciência do que estão sofrendo ou exercendo, contribuindo então para um espaço de exclusões e invasões. 


\section{PADRÕES DE BELEZA E OS TRANSTORNOS ALIMENTARES}

Concomitantemente com mulheres influenciadoras que contribuem, mesmo que inconscientemente e de forma não proposital, para o culto ao corpo belo e a pressão estética há influenciadoras que tem vindo a público relatar que são também vítimas dessa pressão estética bem como portadoras de transtornos alimentares. (TA). Um exemplo atual, a influenciadora Rica de Marre, que após ser alvo de vários comentários maldosos discorridos sobre seu corpo e peso, desabafa por meio do Instagram que tomou inibidor de apetite e passou mal logo em seguida.

A pressão social e cultural não é fator causal, porém pode ser fator desencadeador para TA. De acordo com a literatura e autores como Hercovici e Bay (1997) o ideal de magreza é um dos fatores culturais centrais para o aumento desses transtornos, principalmente a bulimia e a anorexia nervosa.

O padrão de beleza construído pela sociedade é, inconscientemente, incorporado pela mesma. Atualmente, em consequência da busca desse padrão, houve o surgimento de uma obsessão pelo controle e modelagem do corpo, bem como a preocupação e o medo da obesidade. (ANDRADE e BOSI, 2003). A anorexia e a bulimia são transtornos prevalentes nas mulheres e que estão, de modo intrínseco, relacionado ao ideal de feminilidade.

Os transtornos alimentares, de acordo com o DSM V, são caracterizados por indivíduos que apresentam uma ideia prevalente envolvendo a preocupação excessiva com o peso e a forma corporal (medo de engordar), que leva a se engajarem em dietas extremamente restritivas ou a utilizarem métodos inapropriados para alcançarem o corpo idealizado. Na bulimia são frequentes os episódios de comer excessivo (acompanhado com muito culpa) e seguido de algum método purgativo como laxantes e vômitos induzidos já a anorexia é caracterizada pelo peso consistemente abaixo do mínimo de normalidade.

Kelnner (2001) considera que a busca incessante do corpo perfeito leva a conflitos com nossos limites humanos e acabam sendo, muitas vezes, desencadeadores para 
sintomas psicopatológicos, como depressão, ansiedade ou melancolia e transtornos alimentares. Para ser aceito o sujeito acaba se submetendo a situações sem considerar seu corpo com fatores fisiológicos, biológicos, genéticos, situação chamada por alguns autores de setting point.

Na visão psicanalítica, o transtorno alimentar é um distúrbio produzido pela interação do corpo com o meio e o aumento dos casos de transtornos alimentares pode ser entendido também como efeito do modo de organização da sociedade na qual o alimento não promove a união. Para Freud, em Totem e Tabu, o alimento tem como função promover laço social e quando é incapaz de cumprir essa função, o alimento adquire atributo de angústia. Os TA como anorexia e bulimia são então, manifestações de um sofrimento psíquico relacionados a uma falha psíquica ligada a ruptura precoce na relação com a figura materna do sujeito.

Os TA são advindos de um investimento libidinal materno inadequado (insuficiente ou exagerado), havendo falhas na constituição do corpo como objeto psíquico. Nesse sentido, a relação mãe-filha acaba sendo problemática, pois o investimento libidinal decorre-se em uma fusão na identificação entre ambas, não ocorrendo à particularização entre a mãe e a filha. Dessa forma, os sintomas dos transtornos alimentares são expressos e criados como forma de defesa pelo ego.

\subsection{ANOREXIA NERVOSA}

O termo anorexia vem do grego orexis, que significa desejo em geral (e não apenas desejo de comer), precedido do prefixo a de negação, resultando assim em negação do desejo. Ou seja, o indivíduo anoréxico muitas vezes sentem fome, mas negam o desejo.

Os critérios diagnósticos para a anorexia nervosa, de acordo com o DSM V são: restrição da ingesta calórica em relação às necessidades, resultando em um peso corporal extremamente baixo se considerado o contexto de idade, gênero, trajetória do desenvolvimento e saúde física; peso significativamente baixo (definido como um peso inferior ao peso mínimo normal) ou menor do que o minimamente esperado, para 
crianças e adolescentes, geralmente procede de um medo intenso de ganhar peso, ou de comportamentos rotineiros que interfere no ganho de peso, mesmo este estando significativamente baixo. Perturbação com o próprio peso ou forma corporal são vivenciados, além da influência indevida do peso ou da forma corporal na auto avaliação ou ausência persistente de reconhecimento da gravidade do baixo peso corporal atual.

Na psicanálise a anorexia é considerada como um distúrbio da oralidade, na qual ainda não há uma diferenciação entre o indivíduo e o objeto. Então, o ato de não comer nos casos de anorexia está relacionado a uma estratégia de separação do outro, ou melhor, estratégia de separar do domínio do olhar materno provendo um modo de resistência e de possível afirmação do seu próprio desejo de um eu autônomo.

Ou seja, esse "não comer, recusar o elo fundamental da relação primeira com a mãe, parece ser um ótimo começo a se encenar essa vingança, ou protesto" (GOGARTI, 2002, p. 119). Através da recusa do alimento, o sujeito visa barrar o outro-mãe, tentando inverter esta relação de dependência frente a ela.

\subsection{BULIMIA NERVOSA}

O termo bulimia, que remonta a Antiga Grécia, deriva do termo grego "bous", boi e "limos", fome, isto é, "fome de boi" e caracteriza-se pela ingestão de grande quantidade de alimentos em curto período de tempo, seguida por métodos purgativos como o uso de laxantes e o vômito autoinduzido.

Os critérios diagnósticos de bulimia nervosa, de acordo com o DSM, se caracterizam por episódios recorrentes de compulsão alimentar; comportamentos compensatórios inapropriados recorrentes a fim de impedir o ganho de peso; a compulsão alimentar e os comportamentos compensatórios inapropriados ocorrem, em média, no mínimo uma vez por semana durante três meses; a auto avaliação é indevidamente influenciada pela forma e pelo peso corporais e a perturbação não ocorre exclusivamente durante episódios de anorexia nervosa. 
$\mathrm{Na}$ visão psicanalítica, o ato bulímico compreende a vivência do ser completo e de ter o falo, apresenta- se como uma prática pulsional como forma de gozo que contrasta com o sujeito do inconsciente.

\section{CONCLUSÃO}

Como vimos, o corpo feminino é construído historicamente e culturalmente. Desde os séculos XII o corpo da mulher é considerado como corpo para o outro, ou seja, um corpo para satisfazer a demanda do homem. Através de várias mudanças, atualmente diante a influência da mídia e do capitalismo, o culto ao corpo belo emergiu se em novas práticas patológicas voltadas para o próprio corpo como ocorre nos casos de transtornos alimentares. Os transtornos alimentares são causados por variáveis multifatoriais, porém no artigo foi considerado o fator cultural e de ordem psicanalítica. Considera-se então necessário uma forma de tratamento multidisciplinar e cabe ao psicólogo estabelecer e reestruturar os vínculos estabelecidos entre o indivíduo anoréxico ou bulímico com suas figuras parentais a fim de percorrer a uma identidade mais autêntica, ademais é necessário que vincule o corpo belo como um corpo saudável, livre de pressões estéticas.

\section{REFERENCIAS}

American Psychiatric Association. (2014). Manual diagnóstico e estatístico de transtornos mentais: DSM-5 (5a ed.; M. I. C. Nascimento, Trad.). Porto Alegre, RS: Artmed.

ANDRADE, A; BOSI, M. L. Mídia e subjetividade: impacto no comportamento alimentar feminino. Revista de Nutrição, [S.L.], v. 16, n. 1, p. 117-125, jan. 2003.

BERNARDES, T. Adolescência, Mídia E Transtornos Alimentares: Uma Revisão Bibliográfica. 2010. 34 f. TCC (Graduação) - Curso de Enfermagem, Universidade Federal do Pampa, Uruguaiana, 2010.

BIRMAN, J. (1998). A epopéia do corpo. Nostalgias. Em Bastos, L. A. M. Eucorpando. O ego e o corpo em Freud (pp. 09-24). São Paulo: Editora Escuta. 
BERNARDO, João. Democracia totalitária: teoria e prática da empresa soberana. São Paulo: Cortez, 2004.

BITTAR, C; SOARES, A. Mídia e comportamento alimentar na adolescência. Cadernos Brasileiros de Terapia Ocupacional, [S.L.], v. 28, n. 1, p. 291-308, 2020. Editora Cubo.

FLOR, G. Corpo, mídia e status social: reflexões sobre os padrões de beleza. Rev. Estud. Comun, Curitiba, v. 23, n. 10, p. 267-274, dez. 2009.

FORTES, I. Anorexia: o traço da obstinação na clínica psicanalítica. Revista Latinoamericana de Psicopatologia Fundamental, [S.L.], v. 14, n. 1, p. 83-95, mar. 2011.

FOUCAULT, M. Vigiar e punir: nascimento da prisão. Rio de Janeiro: Vozes, 2009b.

FOUCAULT, M. Os corpos dóceis. Vigiar e punir: nascimento da prisão. $29^{\underline{a}}$ ed. Tradução de Raquel Ramalhete. Petrópolis, RJ: Vozes, 2004a, p. 125-52.

GOELLNER, Silvana Vilodre. "A produção cultural do corpo.” In: LOURO, Guacira Lopes; NECKEL, Jane Felipe; GOELLNER, Silvana Vilodre. (Orgs.) Corpo gênero e sexualidade: um debate contemporâneo. Petrópolis, Vozes, 2003.

GARCIA-ROZA, L. A. O mal radical em Freud. Rio de Janeiro; J. Zahar, 1990.

KELLNER, Douglas. A cultura da mídia. Bauru, SP: EDUSC, 2001.

NASCIMENTO, C; PRÓCHNO C. C; SILVA, L. C. O corpo da mulher contemporânea em revista. Fractal: Revista de Psicologia, [S.L.], v. 24, n. 2, p. 385404, ago. 2012.

NUNES, S. A. O feminino e seus destinos: maternidade, enigma e feminilidade. In BIRMAN, Joel. Feminilidades. Rio de Janeiro: Contra Capa, 2002, p.35-57. 
Revisão de Bourdieu, Pierre (2012), Sur l'État. Cours au Collège de France (19891992). Paris: Raisons d'Agir/Seuil, 672 pp.

SILVA, H; REY, S. A beleza e a feminilidade: um olhar psicanalítico. Psicologia: Ciência e Profissão, [S.L.], v. 31, n. 3, p. 554-567, 2011.

SILVA, M. Espelho, espelho meu. Brasília, 2018.

SOUTO, S; FERRO-BUCHER, J. Práticas indiscriminadas de dietas de emagrecimento e o desenvolvimento de transtornos alimentares. Revista de Nutrição, [S.L.], v. 19, n. 6, p. 693-704, dez. 2006.

VALDIVIA, O. Psicanálise e feminilidade: algumas considerações. Psicologia: Ciência e Profissão, [S.L.], v. 17, n. 3, p. 20-27, 1997.

VIANNA, C. Da imagem da mulher imposta pela mídia como uma violação dos direitos humanos. Minas Gerais.

WOLF, N. O mito da beleza, 1990.

Enviado: Setembro, 2020.

Aprovado: Setembro, 2020. 